\title{
A Stratified Temporal Spectral Mixture Analysis Model for Mapping Cropland Distribution through MODIS Time-Series Data
}

\author{
Jinshui Zhang ${ }^{1,2}$, Fenghua Wei ${ }^{2}$, Peijun $\mathrm{Sun}^{2}$, Yaozhong Pan $^{1,2}$, Zhoumiqi Yuan ${ }^{2} \&$ Ya Yun ${ }^{2}$ \\ ${ }^{1}$ State Key Laboratory of Earth Surface Processes and Resource Ecology (ESPRE), Beijing Normal University, \\ Beijing, China \\ ${ }^{2}$ College of Resources Science \& Technology, Beijing Normal University, Beijing, China \\ Correspondence: Fenghua Wei, College of Resources Science and Technology, Beijing Normal University, \\ Beijing, China, ON, No. 19, XinJieKouWai St., HaiDian District, Beijing, P. R. China. Tel: 86-5880-2932. E-mail: \\ weifh@gj.stats.cn
}

Received: April 19, 2015 Accepted: May 22, 2015 Online Published: July 15, 2015

doi:10.5539/jas.v7n8p95 URL: http://dx.doi.org/10.5539/jas.v7n8p95

\begin{abstract}
The aim of study was to develop a stratified temporal spectral mixture analysis (STSMA) for cropland area estimation using MODIS time-series data to address the mixed pixel problem caused from coarse resolution. The proposed method used thematic map from MODIS classification as prior knowledge to determine the endmember set for each sub-region input into SMA model. The results indicated the STSMA method performing better in estimating the cropland land. RMSEs (from 0.25 to 010 ), $R^{2} \mathrm{~s}$ (from 0.65 to 0.89 ) and bias (0.02), used as three accuracy assessment parameters, and STSMA obtained higher overall accuracy in the entire study area, at individual pixel scale to 0.10 at $10 \times 10$ pixels scale, representing higher performance compared to the conventional spectral mixture analysis (SMA) method at each pixel scale. In single-season crop, dual-season crop, natural vegetation and non-vegetation dominated landscape, the similar success from STSMA is also achieved because the suitable endmember set was set for the proposed model to ensure the accuracy of cropland estimation to address the conventional SMA colinearity problem at some degree.
\end{abstract}

Keywords: cropland, endmember, landscape, spectral mixture analysis (SMA), stratified temporal spectral mixture analysis (STSMA)

\section{Introduction}

Timely and accurate cropland distribution detection and area estimation is of great significance to a wide group of end-users who can manage crop planting pattern or harmonize agricultural economic market (Potgieter, Apan, Hammer, \& Dunn, 2010; Pan, Li, Zhang, Liang, Zhu, \& Sulla-Menashe, 2012). This is also vital variable for researcher to analyze global carbon, water and nutrient cycles (Bondeau et al., 2007).

Remote sensing to record the main phenology characteristics of cropland has been proven as an effective tool to map cropland. The moderate remote sensing images with suitable pixel resolution were usually used for cropland estimation, such as single-period remote sensing classification or multi-temporal image detection method (Nuarsa, Nishio, \& Hongo, 2011). Taking into account the satellite return period, the acquisition of amounts of cloud-free imagery for mapping cropland using moderate resolution remote sensing images is evitable problem for operational implementation over large areas (Lobell \& Asner, 2004).

The frequent acquisition of remote sensing data from the Moderate Resolution Imaging Spectroradiometer (MODIS) provides an exciting opportunity for monitoring agricultural systems (Lobell \& Asner, 2004; Wardlow, Kastens, \& Egbert, 2006; Pan et al., 2012). Many researchers discern the different crop types by identifying the spectra difference during the crop growing seasons (Arvor, Jonathan, Meirelles, Dubreuil, \& Durieux, 2011; Biradar \& Xiao, 2011). It is limited that several land covers are within one pixel due to MODIS coarse resolution, which introduces mass of errors in estimating and mapping the cropland area. This is universal phenomenon to estimate the cropland in China because the field parcels are small and fragmented. Hence, it is common that the mixture of several land covers exists within one pixel.

Cropland here is defined as the cultivated area where is planted with crops during one year, including single season crop and the dual season crop. Considerable efforts have been made for unmixing MODIS mixed pixel to 
extract cropland fraction in order to address the mixed pixel problems (Lobell \& Asner, 2004; Pan et al., 2012). In those approaches, the assumption is that the MODIS phenology curve is constant during the crop growing season and can be used for mapping cropland distribution using the time-series data. Usually, two kinds of methods are carried out for cropland identification in pixel scale using MODIS series data. The first one is a combined method with moderate remote sensing and MODIS data (Pan et al., 2012). The perquisite of moderate resolution remote sensed data, such as Landsat TM (Thematic Mapper), for this model was used for extracting sub-region crop as the actual crop value comparing with MODIS. So, the cropland derived from moderate resolution remote sensing data, such as TM, as the prior-knowledge was introduced to MODIS time-series data for constructing model between MODIS and actual fraction to extract the whole region cropland (Ozdogan \& Woodcock, 2006; Pan et al., 2012). In this model, the moderate key phonological image remote sensing images are necessary to extract the sub-region actual cropland fraction, while it is not practical to obtain these images due to cloud reason, which limit the model application. Another method is spectral mixture analysis (SMA) to produce cropland fraction which can address the mixed pixel problem effectively. SMA have been widely applied for many aspects for land cover acreage estimation using MODIS data (Roberts et al., 1998; Wu \& Murray, 2003; Yang, Matsushita, \& Fukushima, 2010). For agriculture system, there is still little research which focuses on mapping the cropland with SMA model using MODIS data. Lobell and Anser (2004) firstly introduced the SMA model to estimate wheat acreage and analyzed the usefulness and suitability of the proposed method at different scales. The result showed that SMA model can solve the mixed pixel problem in different agricultural landscape and achieve similar accuracy performance of wheat acreage consistent with TM. In China, the SMA method has in-depth potential for cropland mapping using MODIS due to fragmented planted parcels which are widely distributed across China. Hence, it is of great significance to introduce SMA model for mapping cropland of China.

From the previous study on using SMA model for land cover fraction estimation, the endmember selection is a basic step to determine the signatures of pure land cover for SMA model. Usually, the endmember library was constructed directly from the original image, which can remove the atmosphere effects to some degree (Wu \& Murray, 2003). The global endmember set, such as crops, vegetation and non-vegetation, are extracted across the entire original remote sensing image, and are applied for unmixing each pixel to extract the land cover fraction (Lobell \& Asner, 2004). However, the colinearity problem is a common and inevitable problem for SMA to map land cover (Van der Meer \& Jia, 2012). The image stratification suggested by Van deer Meer (2012) was one of effective way to address the problem. In Zhang et al.'s (2014) research, the prior-knowledge spectral mixture analysis model (PKSMA) was applied to map impervious surface effectively. In this model, the prior knowledge, such as high-density urban and low-density urban, which was the basis for endmember set combination determination for SMA analysis, was generated from remote sensing image directly. Compared to the conventional SMA model, the more suitable endmember was selected for PKSMA. The succeeded experience of PKSMA can be extended to cropland mapping.

The aim of this paper is to develop a stratified temporal spectral mixture analysis (STSMA) model to determine endmember set from agricultural planting pattern for mapping cropland distribution using 16-day composited $250 \mathrm{~m}$ MODIS NDVI data. The root mean square error (RMSE), the correlation coefficient $\left(R^{2}\right)$ and bias as accuracy assessment parameters is used to test the proposed method performance.

\section{Stratified Temporal Spectral Mixture Analysis}

As we known, SMA model is applied for unmixing mixed spectral images with the aim to quantify the relative abundance of each land cover due to several land covers within one pixel (Van der Meer \& Jia, 2012). The linear spectral mixture analysis (LSMA) as a simple spectral mixed model for estimating land cover fraction assumes that the spectrum measured by a sensor is a linear combination of the spectra of all components within one pixel (Lu, 2006; Van de Voorde, Roeck, \& Canters, 2009; Van der Meer \& Jia, 2012).

A stratified temporal spectral mixture analysis (STSMA) model which is originated from the convectional spectral mixture analysis model (SMA) is developed in this paper. As discussed by Van de Meer et al. (2013) and Zhang et al. (2014), image stratification is an effective way to address the colinearity problem of SMA for land cover mapping. For the agricultural landscape, similar characteristic crop are concentrated at regional scale due to uniform climate and peasant management practice. For example, the single seasonal crop is usually as autumn crop, such as maize, cotton, and etc. While, the dual seasonal crop pattern is the crop rotation of summer and autumn crop, such as from winter wheat to maize. All these result in the particular clustered agricultural landscape pattern. Taking into account the different regional scale agricultural landscape, we can use the agricultural planting pattern as the prior-knowledge to determine the endmembers combination in each strata for SMA to map the cropland. 
The stratified temporal SMA (SSMA) based on agricultural landscape introduce LSMA model for mapping cropland land using time-series MODIS data using strata information to determine endmember combination, which can be defined as,

$$
\begin{gathered}
R_{b}^{m}=\sum_{i=1}^{N^{m}} f_{i} R_{i, b}+e_{b} \\
\sum_{i=1}^{N} f_{i}=1 \quad f_{i} \geq 0 \\
S=f_{i}^{1} \cup \ldots f_{i}^{m} \ldots \cup f_{i}^{M}
\end{gathered}
$$

Where $R_{b}^{m}$ is the reflectance of band $b$ of $i$ th land cover in $m$ th statum of the image. $N^{\mathrm{m}}$ is the number of endmembers set in $m$ th statum, $R_{i, b}$ is the reflectance of endmember $i$ th in band $b$, and $e_{b}$ is the residual error. The $m$ ranges from 1 to $M$, which $M$ is the number of strata. The fraction of each endmember in each stratification can be calculated using the least-square method. $f_{i}^{m}$ means the fraction map of $i$ land cover type in $m$ th strata. $S$ is the cropland fraction result. The U represents the mosaic conduction with fi. Model fitness is generally assessed by the residual error or RMS over all image bands:

$$
R M S=\sqrt{\sum_{b=1}^{B N} e_{b}^{2} / B N}
$$

Where $\mathrm{BN}$ denotes the number of selected bands in the image.

From Equations (1)-(4), it is obvious that the STSMA for cropland estimation adopts specific endmember set for mixed pixels unmixing in each strata determined by the prior-knowledge as the agricultural planting pattern, which is different from the conventional SMA.

\section{Study Area and Materials}

\subsection{Study Area}

In this study, we selected area located in North China Plain (Figure 1), which covers the several counties of Hebei and Shandong province. It is sub-humid continental monsoon climate, where it is dry and cold in winter, hot and rainy in summer and severe drought in spring. Wheat as the summer harvested crop and maize as the autumn harvested crop are dominated in this region. Winter wheat planted in October-November and harvested in June of the following year is the crop covering roughly more than 50\% of the planted area (Ren, Chen, Zhou, $\&$ Tang, 2008). Maize planted usually from May to June and harvested in September- October accounts for about $60-70 \%$ of the grain planted areas. Nowadays, the farmers prefer to plant maize as the single crop for its' high-yield production comparing to wheat production in this area, which leads to amount of fallow cultivated land left. 


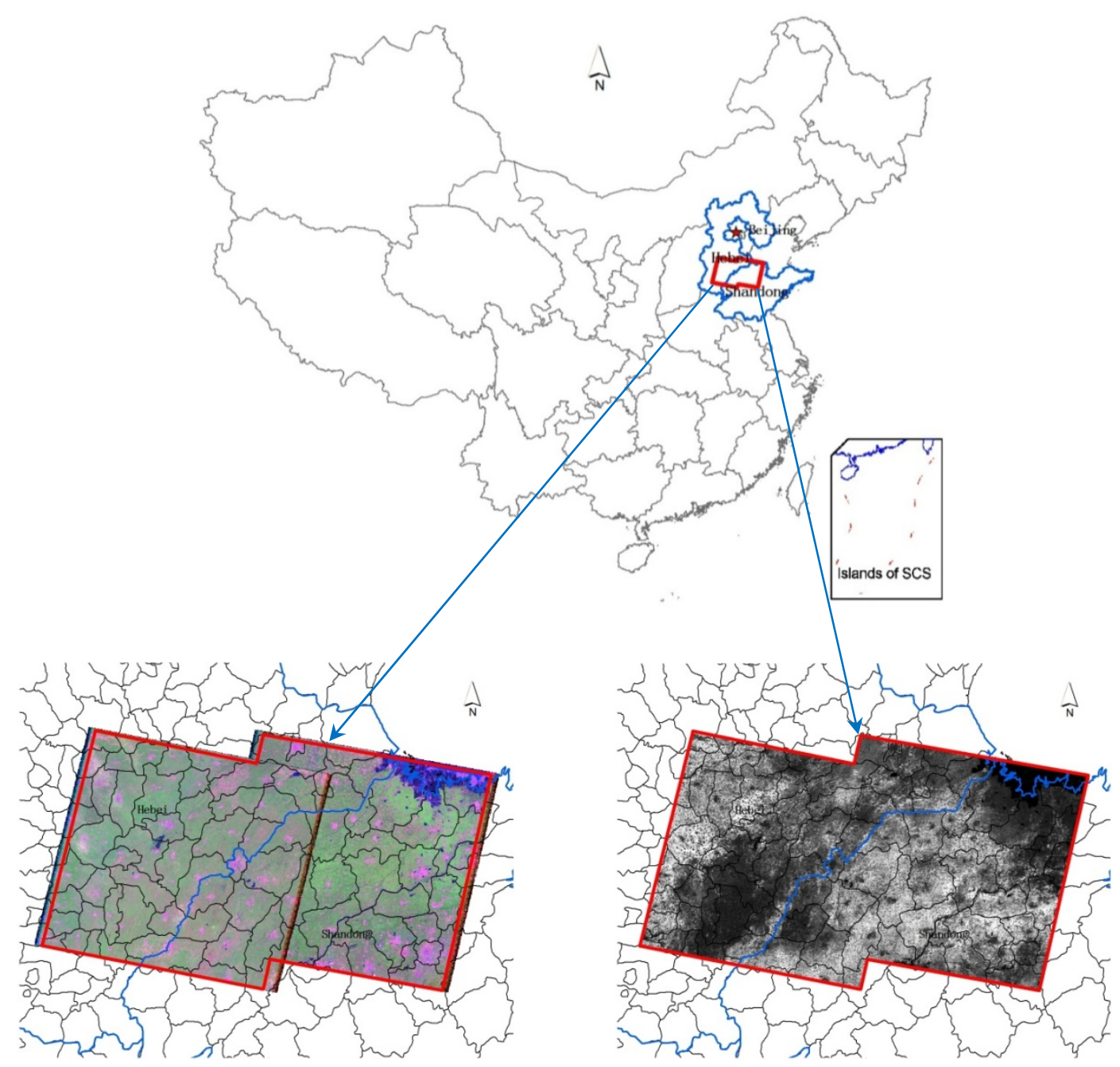

Figure 1. The locations of study area and their false-color composited imager, Landsat TM (bands Combination: $\mathrm{RGB}=6,4,3)$ and MODIS EVI gray image

\subsection{Materials and Pre-Processing}

The data set used in this study included four moderate-spatial resolution images, three Landsat Thematic Mapper (TM) images and one Landsat Thematic Mapper Plus $(\mathrm{ETM}+)$ image (download url: http://earthexplorer.usgs.gov), and MODIS-EVI time series data at $250 \mathrm{~m}$ resolution. Table 1 is the used dataset collection.

Table 1. Description of remote sensing dataset

\begin{tabular}{lc}
\hline Satellite & Remote sensing imagery \\
\hline Landsat 5, 7 & Landsat TM \\
& 122/34, April 8, 2009 \\
$122 / 34$, August 30, 2009 \\
123/34, September 22, 2009 \\
Landsat ETM+ \\
123/34, May 25, 2009 \\
16-day MODIS_EVI and composite day of the year from \\
MODIS
\end{tabular}




\subsubsection{Moderate Resolution Images}

In this study, we used four moderate resolution remote sensing images for extracting cropland as reference data for accuracy assessment. The four images were re-projected to Albers Equal Area projection. The black line data of the ETM+ image which influence the further cropland detection was eliminated with landsat gapfill module embedded in ENVI software (http://www.yale.edu/ceo/Documentation/Landsat_ETM_Gap_Fill.pdf). Finally, a little part of the image was truncated visually because some of the overlap area from the adjacent remote sensing images is useless for further analysis.

Remote sensing images with a spatial resolution ranging from $10 \mathrm{~m}$ (such as SPOT5 HRG) to $30 \mathrm{~m}$ (such as Landsat TM or ETM+) are applied for cropland identification in most landscapes (Carfagna \& Gallego, 2005). In North China Plain, fragmented field parcels are distributed widely which is still a limited factor for cropland estimation using MODIS. While it is suitable for moderate resolution remote sensing image, such as Landsat TM or ETM+ with 30m resolution, to map the cropland which have been widely used for agriculture investigation (Uarsa, Nishio, \& Hongo, 2011; Wästfelt, Tegenu, Nielsen, \& Malmberg, 2012). Compared to MODIS with $250 \mathrm{~m}$ resolution, the resolution of Landsat image is enough and sufficient for cropland detection and can be considered as the reference value to validate accuracy of the cropland derived from the coarse resolution remote sensing imagery, such as MODIS (Lobell \& Asner, 2004; Pan et al., 2012).

Analysis on Landsat images from Figure 2, the comparison of the single season crop (SSC) as the autumn crop and the dual season crop (DSC) as the rotation from summer crop to autumn is presented. From those images, the SSC is fallow in spring and left to plant autumn crop in May (Figures $2 \mathrm{a} \& 2 \mathrm{~b}$ ). The dual season crop is planting with crops across one year (Figures $2 \mathrm{c} \& 2 \mathrm{~d}$ ).

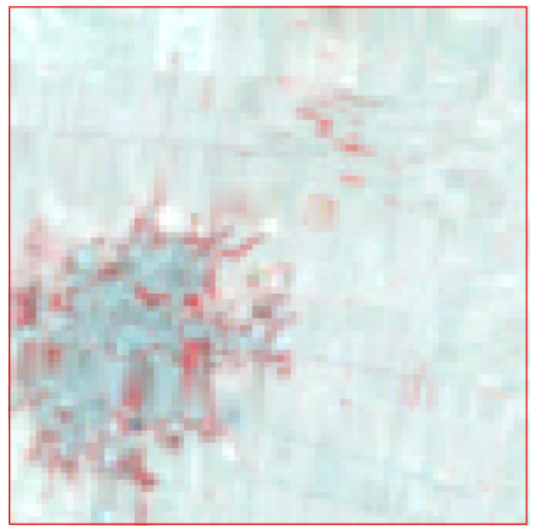

(a)

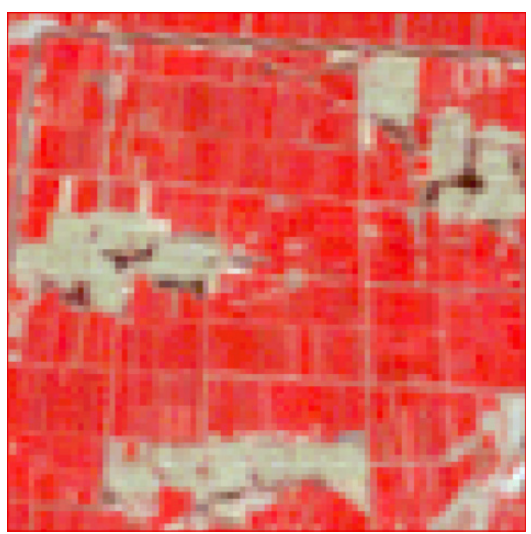

(c)

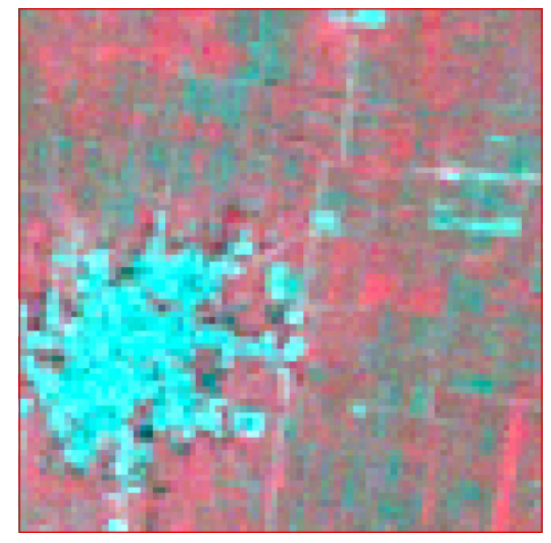

(b)

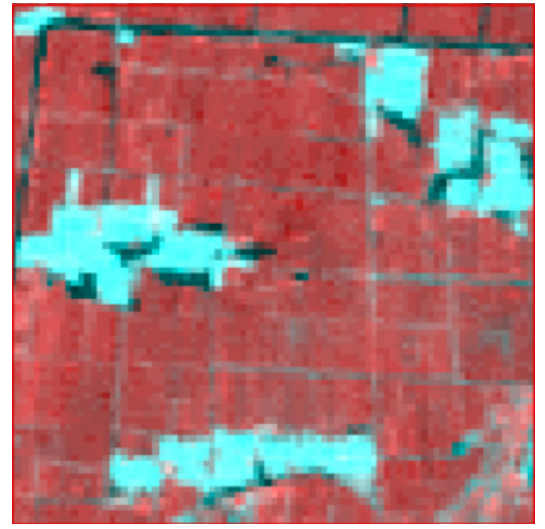

(d)

Figure 2. sub-views of cropland in two date Landsat TM Images(bands Combination: RGB = 4, 3, 2). (a) SSC dominated region from TM image acquired April 8, 2009; (b) SSC dominated region from TM image acquired August, 30 2009; (c) DSC dominated region from TM image acquired April 8, 2009; (d) DSC dominated region from TM image acquired August 30, 2009 
According to the crop phenology of this area, the acquired Landsat TM images recorded the main crop growing characteristics, which is the basis for cropland classification. We classified the four remote sensing images using support vector machine method, which is popular and advanced classifier for land cover mapping (Mountrakis, Im, \& Ogole, 2011). The classification scheme that include crop, tree, bare land, urban and water, is defined. The urban area which is similar with bare land spectrally can be considered as bare land. The process for determining the SSC, DSC and cropland (CL) is as follows.

$$
\begin{gathered}
\mathrm{SSC}=\operatorname{crop}_{T_{1}} \mathrm{I} \text { crop }_{T_{2}} \\
\mathrm{DSC}=\text { bareland }_{T_{1}} \mathrm{I} \text { crop }_{T_{2}} \\
\mathrm{CL}=\mathrm{SSC} \mathrm{UASC}
\end{gathered}
$$

The SSC is pixels collection where the pixels in $T_{1}$ was identified as bare land and as crop in $T_{2}$. While the DSC can be defined as those pixels classified as crop in $T_{1}$ and $T_{2}$, that represents the rotation from winter crop to autumn crop. In the end, the CL is the union set of SSC and DSC. U means union operation.

Although cropland map as CL derived from the Landsat were not extensively validated, the well-known ability of Landsat to map cropland allowed us to assign these maps as "actual value" or reference data for subsequent evaluation of cropland distribution extracted from MODIS time-series data.

\subsubsection{MODIS Pre-Processing}

Taking into account of enhanced vegetation index (EVI) product which is less susceptible than normalized difference vegetation index (NDVI) to biases resulting from cloud and haze contamination and both vegetation indices have similar seasonal responses (Wardlow, Egbert, \& Kastens, 2007), we used EVI directly for further study. The MODIS EVI time series data used in this study was from 16-day MODIS EVI reflectance data at 250 $\mathrm{m}$ resolution from the MOD13Q1 product ranging from January to December containing 23 data layers, which is usually applied for crop identification (Tan, Lymburner, Thankappan, \& Lewis, 2011; Thenkabail \& Wu, 2012). The MODIS data were mosaicked and re-projected from Sinusoidal to Albers Equal Area projection. A Savitzky-Golay filter was applied for the MODIS-EVI time series to minimize the effects of cloud cover (Chen et al., 2004).

The twenty typical MODIS pixels were selected from the filtered remote sensing image to analysis the phenology of the four typical land cover classes across a year, including single seasonal crop land, dual seasonal crop land, non-crop and non-vegetation. The filtered pixels temporal-series response was picked and listed as Figure 2.

Each crop has its own unique phenology features according to the crop species but also influenced by climate, soil condition, water supply, cultivation habits, and other environmental factors (Sakamoto et al., 2005). From Figure 3, the curves of time series data from the remote sensing record the phenology features of the four typical land covers. In the SSC region, the autumn crop, such as maize in this area, is the dominant land cover type. The peak of time-series data related to the autumn crop growing from May to September appears around August 13, at that time the crop grow vigorously. The DSC region, where the dominant pattern of the crop rotation of summer and autumn crops, represents the two time-series peaks to record the growth characteristics of above the two crops. For natural vegetation (NV), such as tree, which is dominated, the life cycle spans from March to November and the width of only one profile peak is wider than that of SSC. For non-vegetation (Non_V) including water and bare land, the average EVI value is low to denote the obvious difference from those of the above three land covers. 


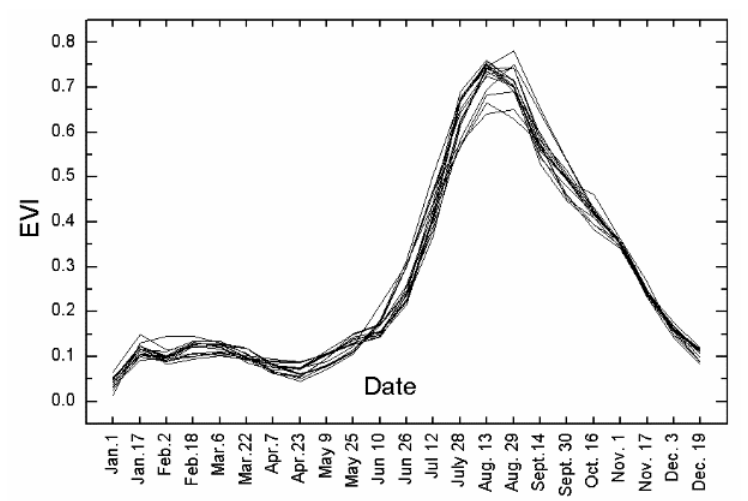

(a)

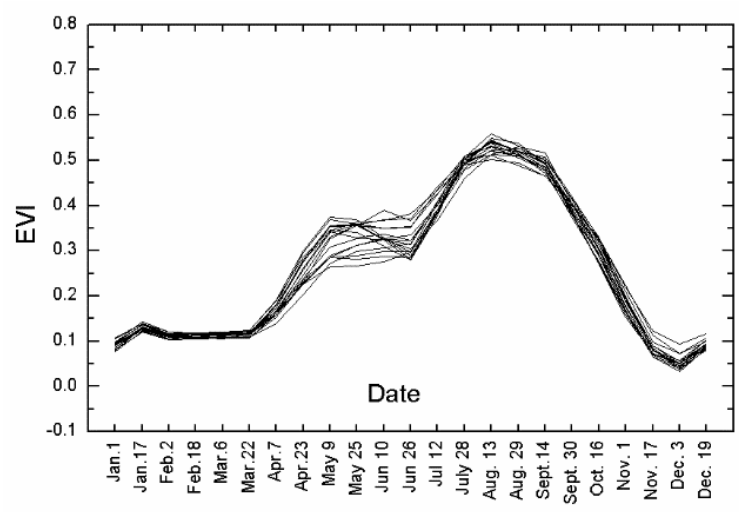

(c)

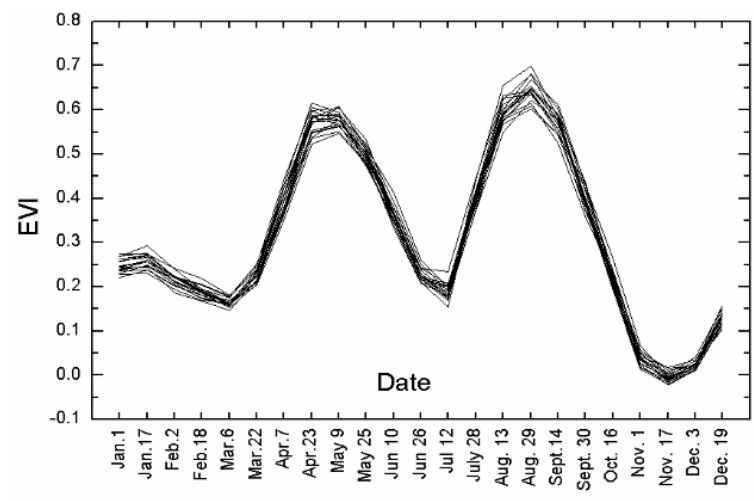

(b)

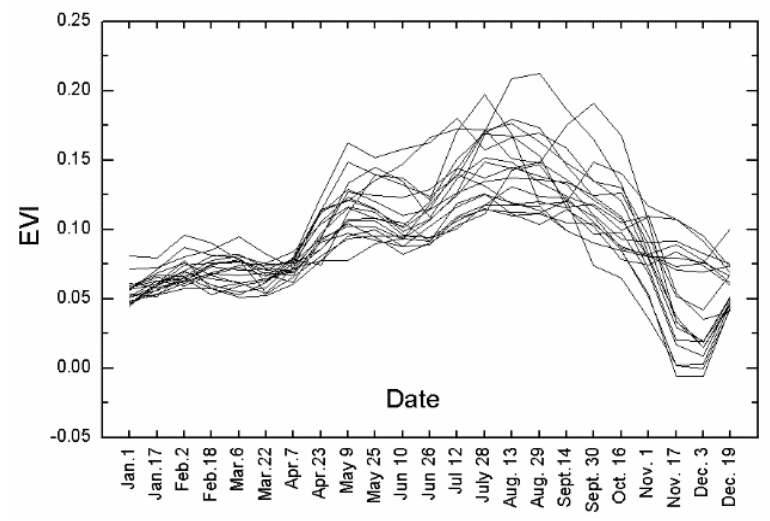

(d)

Figure 3. Enhanced vegetation index (EVI) temporal profile for the four typical land cover classes. (a) SSC temporal profile, (b) DSC temporal profile, (c) non-crop temporal profile, (d) non-vegetation temporal profile

\section{Methodology}

The four main steps, including land covers classification for strata definition, endmember determination in each strata, mapping cropland using STSMA and accuracy assessment, were described below (Figure 4). 


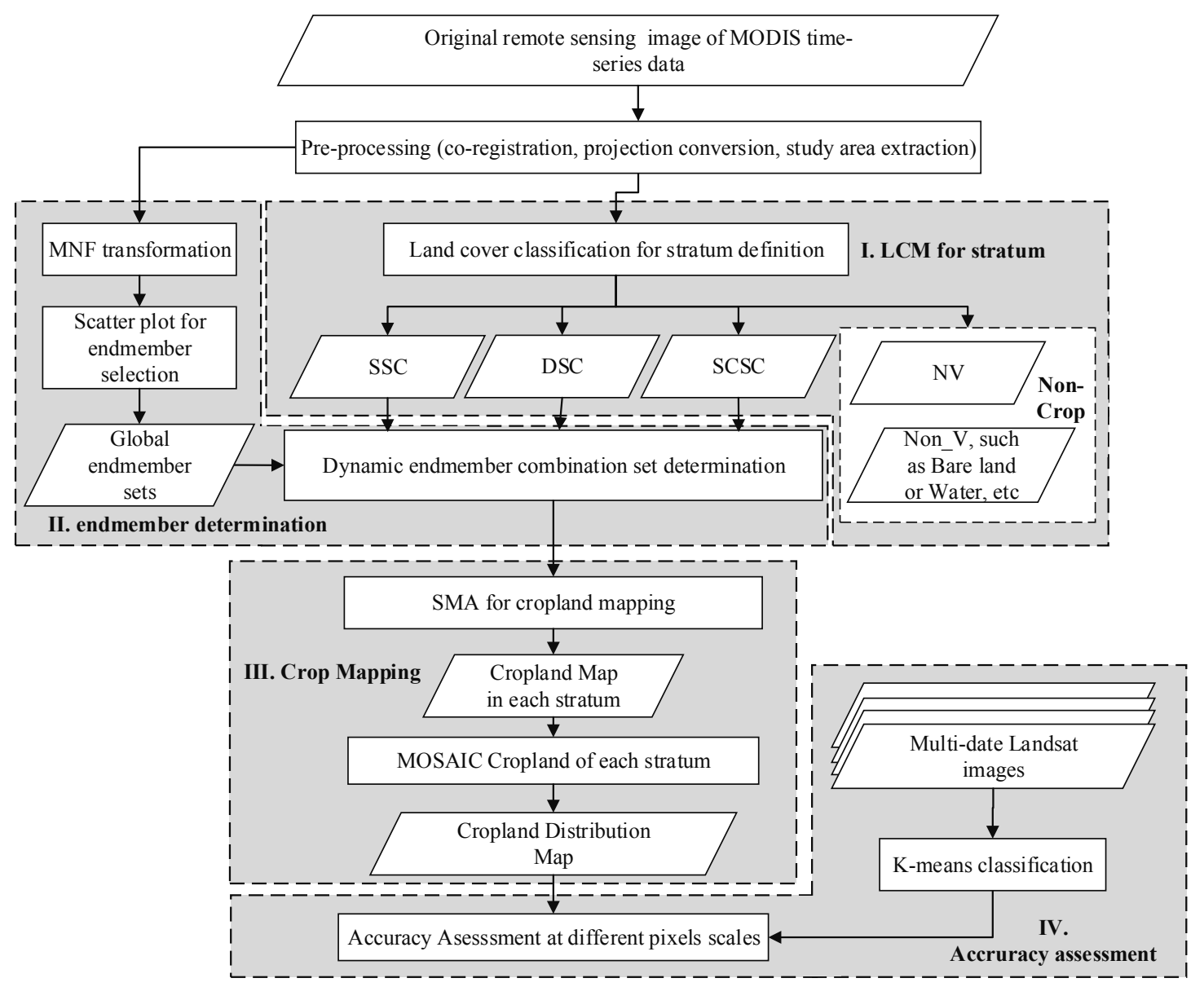

Figure 4. Technology Flowchart of STSMA

\subsection{Land Covers Classification for Strata Definition}

The agricultural landscape represents uniform characteristics in remote sensing image due to the similar climate factors and management practices in local region. Hence, we can determine uniform agricultural landscape from remote sensing data by using classification method that cluster the similar features within satellite data. K-means as an automated clustered method is usually applied for mapping land cover from MODIS time-series data, called as LCM. Ten kinds of land cover are set and the clustered land cover map was produced which is used as the prior knowledge for endmember set determination. From the analysis of the MODIS feature phenology profiles in this area, each clustered category is defined as the land cover type, including sole-season crop (SSC) representing only one season crop planted which is mainly autumn crop, dual-season crop (DSC) representing summer and autumn crop rotation, sole-dual-season crop (SDSC) representing intermingled crop containing SSC and DSC. Non-crop (NC) represents all the other land cover, mainly including natural vegetation (NV) as tree and non-vegetation (Non_V), such as water and bare land. Hence, the ten clustered classes were reclassified and recoded into the predefined classes. Figure 5 show the classification map including the six land covers types. 200 test points that were selected randomly in each class was interpreted visually with support of multi-date high-resolution TM images and MODIS time-series curve. All the plot points were applied to assess the clustered thematic land cover map accuracy, and $85.29 \%$ represents a satisfied result. From Figure 5, the agricultural landscape was concentrated as clustered block with the similar planting features which are embodied as the different land covers type derived from remote sensing images. Especially, the water, town and tree are the typical NC which can be excluded from the cropland collection directly. Here, the SSC, DSC and SDSC are defined as strata which has the similar crop planting characteristics. 


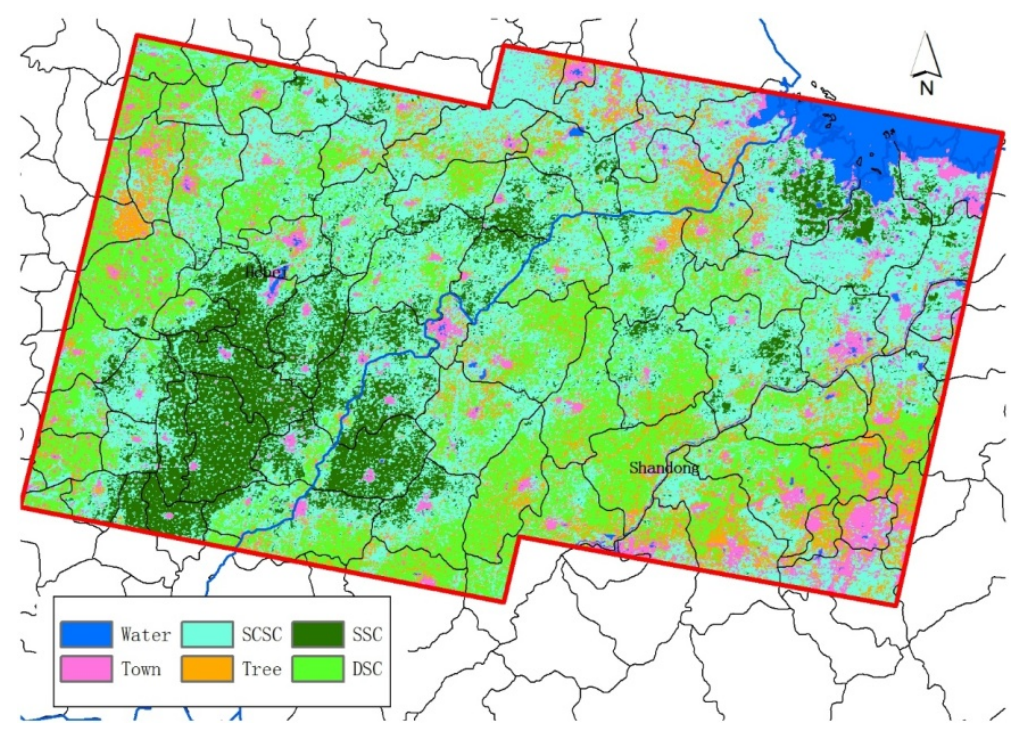

Figure 5. Cropland distribution from MODIS using clustered method

\subsection{Endmember Determination}

Choosing effective endmember set is the critical step for STSMA. Compared to laboratory-based measurements of endmember's spectra, the endmember selection for SMA from remote sensing image directly not only save the work of endmeber collection from the ground, but also eliminate the influence of atmospheric conditions in satellite sensor data (Wu \& Murray, 2003).

It is a usual approach to select representative homogeneous remote sensing pixels through visualizing two-dimensional spectral scatter plots of image band combinations (Rashed, Weeks, Gadalla, \& Hill, 2001). The maximum noise fraction (MNF) was used to guide image endmember selection due to almost majority of the variances on the first two or three components, and reduce the influence of band to band correlation.

In this paper, the MNF transformation has been applied for MODIS data to reduce the dimensions. Selecting the endmembers directly from the extreme pixel of the scatter plots generated from MNF transformed data is a usual method (Wu \& Murray, 2003). This method is introduced for endmember selection from the scatter plot formed by the first three MNF components, which account for more than $75 \%$ of the variance of the original image. The global four kinds of endmember set were selected as SSC, DSC, NV and Non-V for further cropland mapping in STSMA.

\subsection{STSMA Applied for Mapping Cropland}

In the end, the critical step is to determine the endmember set combination on each strata defined from the thematic land cover map using MODIS (LCM) time-series based classification methods. From the classification scheme of LCM, the SSC, DSC, SDSC are the targeted regions where cropland are estimated, whereas NV and Non_V can be defined as zero cropland fraction.

The endmember, SSC, DSC, NV and Non_V, is determined for each strata for cropland mapping using STSMA model. Considering the mixed pixels effect of MODIS and the landscape in this study area, the Non_V component is usually mixed as one of the endmember sets in the SSC and DSC region. Hence, the signatures of Non_V are also used in these two regions with respective SSC and DSC endmember combination. The SDSC, as a special region, is the intermingled area with the components of SSC, DSC and NV and Non_V. Hence, the STSMA is same as the convectional SMA model for cropland mapping in SDSC region using the global endmember sets, SSC, DSC and NV and Non_V.

The cropland fraction map is extracted from the remote sensing image by SMA method for each strata iteratively. The mosaic conduction is applied for fraction map of each strata to produce the final regional cropland map.

\subsection{Evaluation of STSMA Method}

The $R M S E(\mathrm{~s}), R^{2}(\mathrm{~s})$ and bias(s) are used to evaluate the accuracy of cropland estimation derived from MODIS to analyze the change tendency of accuracy performance at each spatial scale (Lobell \& Anser, 2004; Pan, Hu, Zhu, Zhang, \& Wang, 2012a; Pan et al., 2012b). The formulas are defined as follows. 


$$
\begin{aligned}
\operatorname{RMSE}(s) & =\sqrt{\sum_{i=1}^{n}\left(\hat{a}_{i}-a_{i}\right)^{2} / n} \\
R^{2}(s) & =\frac{\operatorname{cov}(a, \hat{a})^{2}}{\operatorname{var}(a) \operatorname{var}(\hat{a})} \\
\operatorname{bias}(s) & =\sum_{i=1}^{n}\left(\hat{a}_{i}-a_{i}\right) / n
\end{aligned}
$$

Where $s$ represents the spatial scale, $n$ is the number of sub-view at the scale s, $\hat{a}_{i}$ is the cropland estimated area, $a_{i}$ is actual cropland the in the $i_{\text {th }}$ sub-view. $\operatorname{cov}(a, \hat{a})$ is the covariance between the "actual" cropland area and estimated are, and $\operatorname{var}(a)$ and $\operatorname{var}(\hat{a})$ are the variance of actual and estimated cropland area.

\section{Results and Discussion}

\subsection{Accuracy Comparison at Different Scales}

The cropland land area estimated from STSMA indicated that the model could succeed in producing the cropland spatial distribution. Figure 6 shows the cropland maps derived from MODIS EVI time-series data by STSMA. In order to validate the accuracy of STSMA method, the convectional SMA model, which is the popular and widely used for land cover mapping to address the mixed pixel problem, was introduced into mapping the cropland using the global endmember collection, including SSC, DSC, NV and Non_V. 

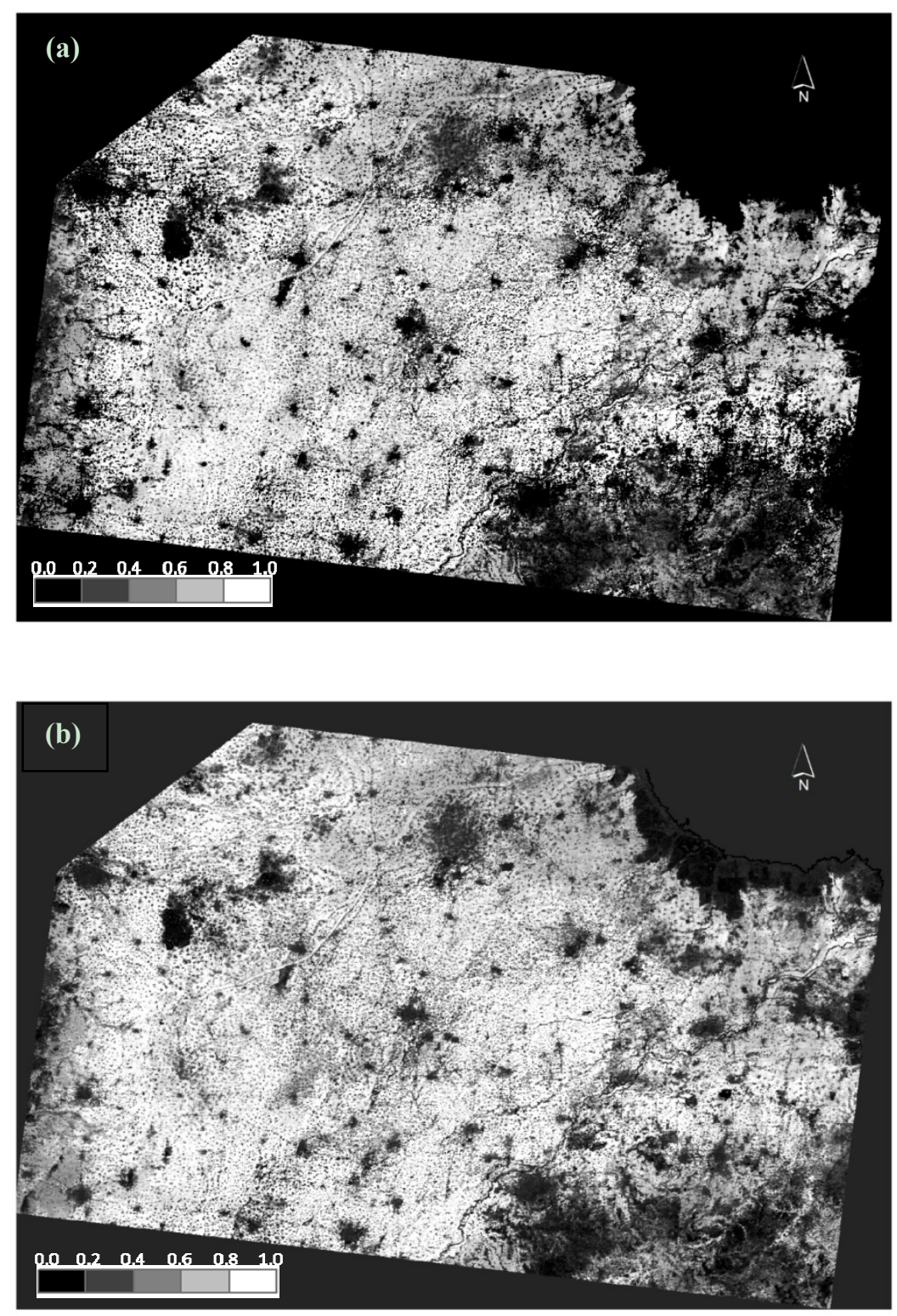

Figure 6. Comparison of cropland fraction using STSMA (a) and conventional SMA model (b)

The cropland area estimated from MODIS using the STSMA model were assessed with the "actual value" using RMSE, $R^{2}$ and bias variables. RMSE decreased roughly from $35 \%$ when evaluated at the scale of individual pixels, to about $12 \%$, at the scale of $5 \times 5$ MODIS pixels. While the pixel scale increases to $6 \times 6$ pixels (about 2.25 $\mathrm{km}^{2}$ ), the RMSE remains stable close to $10 \%$. In addition, $R^{2}$ between the estimated results for STSMA and the "actual value" increased as the scale decreases in a similar logarithmic function from roughly 0.65 at a scale of individual pixel, to more than 0.85 at the scale above $6 \times 6$ MODIS pixels. While the spatial scale varies from individual pixels to $10 \times 10$ pixels, the biases of the estimated cropland were stable at 0.02 denoting the cropland area is little larger than "actual value". Analysis on the above three accuracy parameters, STSMA model shows an exciting result compared to the convectional SMA model. The RMSE of STSMA is lower than those of SMA about $10 \%$ from individual pixel to the scale of $10 \times 10$ pixels. The $R^{2}$ s and biases of STSMA show the similar features comparing to SMA which represent the advantages of STSMA at each spatial level because the proposed method can determine the suitable endmember set for cropland estimation which might address the colinearty problem at some degree.

Owing to the ability of selecting effective endmembers during the process of unmixing mixed pixels can guarantee the high accuracy of mapping the cropland in these regions. But, it may also introduce errors which usually resulted from prior knowledge because of LCM classification accuracy. Hence, higher accuracy in 
mapping cropland from MODIS time-series data can be achieved with better thematic land cover maps in order to determine the optimized endmember sets for SMA.

Sub-region defined by the strata was used to analyze the performance of STSMA at individual pixel' scale (see Table 2). In both SSC and DSC region, the result of the proposed method exhibits satisfactory accuracy to SMA, and about $3 \%$ of $R M S E$ was decreased because the suitable endmember set was introduced to STSMA in order to eliminate the influence of NV, like trees. In SDSC region, the accuracy parameter are equal because the endmember set for STSMA and SMA models are same. In NV and Non-V where non-cultivated land is covered defined by STSMA model, about 0.30 and 0.15 RMSE of STSMA are lower than those of the SMA model. The bias of these two regions, NV and Non_V, from STSMA is negative and a little lower to "actual value" representing a small amount of cropland covered in these regions, which is omitted by STSMA. $R^{2}$ of STSMA in $\mathrm{NV}$ an Non_V represent NaN which denoted Null value because the estimated cropland derived MODIS data is zero in these two regions defined in STSMA model.

Table 2. Accuracy assessment in each strata

\begin{tabular}{llllllll}
\hline \multirow{2}{*}{ Strata } & \multicolumn{3}{c}{ STSMA } & & \multicolumn{3}{c}{ SMA } \\
\cline { 2 - 3 } \cline { 7 - 8 } & $R M S E$ & bias & $R^{2}$ & & $R M S E$ & bias & $R^{2}$ \\
\hline SSC & 0.14 & 0.00 & 0.60 & & 0.17 & -0.04 & 0.49 \\
DSC & 0.22 & 0.10 & 0.66 & & 0.25 & 0.09 & 0.63 \\
SCSC & 0.32 & 0.14 & 0.50 & & 0.32 & 0.14 & 0.50 \\
NV & 0.26 & -0.09 & NaN & & 0.56 & 0.46 & 0.00 \\
Non_V & 0.09 & -0.02 & NaN & & 0.23 & 0.18 & 0.04 \\
\hline
\end{tabular}

Note. $*$ NaN denotes Null value.

\subsection{Plot Level Accuracy Assessment}

One plot was chosen for each strata of different agricultural landscape dominated to evaluate the performance of the STSMA at the plot level. Each plot contained 10 $\times 10$ MODIS Pixels (i.e., $2500 \mathrm{~m} \times 2500 \mathrm{~m}$ ) to reduce the impact from the geometric error between MODIS and Landsat images (Zhang et al., 2014). In the SSC and DSC dominated landscape region where the cropland fraction of "actual value" are $85.36 \%$ and $92.97 \%$ (Figures $8 \mathrm{a}-8 \mathrm{~h}$ ), while those derived from STSMA model are $89.75 \%$ and $94.73 \%$ exhibiting satisfied performance to those of SMA model, $79.67 \%$ and $88.34 \%$, respectively. Analysis on the SSC and DSC land cover pixels of LCM, the cropland fraction by SMA is lower than those of STSMA due to tree, as the global endmember for SMA, while little tree cover can be observed in this region. In the SDSC landscape (Figures 8i-81), the endmeber set for cropland estimation by SMA model is same as those of STSMA, hence the result of cropland fraction is equal each other. For the NV and Non_V landscape (Figures 8i-8p), the result of STSMA model showed exciting performance to SMA model, where zero cropland fraction is defined from LCM. In the NV scenario, the cropland fraction from STSMA is " 0 " which is approximate to "actual value", while that cropland from SMA model is $5.05 \%$. In the Non_V scenario (Figures $8 \mathrm{r}-8 \mathrm{u}$ ), such as village, the cropland fraction was $25.47 \%$ calculated from SMA which is higher than the actual value because the mixture of impervious surface, such as building, and natural vegetation as tree, was unmixed as cropland from this model. The cropland fraction is " 0 " in STSMA model because the most pixels in this plot was classified as Non_V which ensured the cropland fraction estimatin accuracy. 

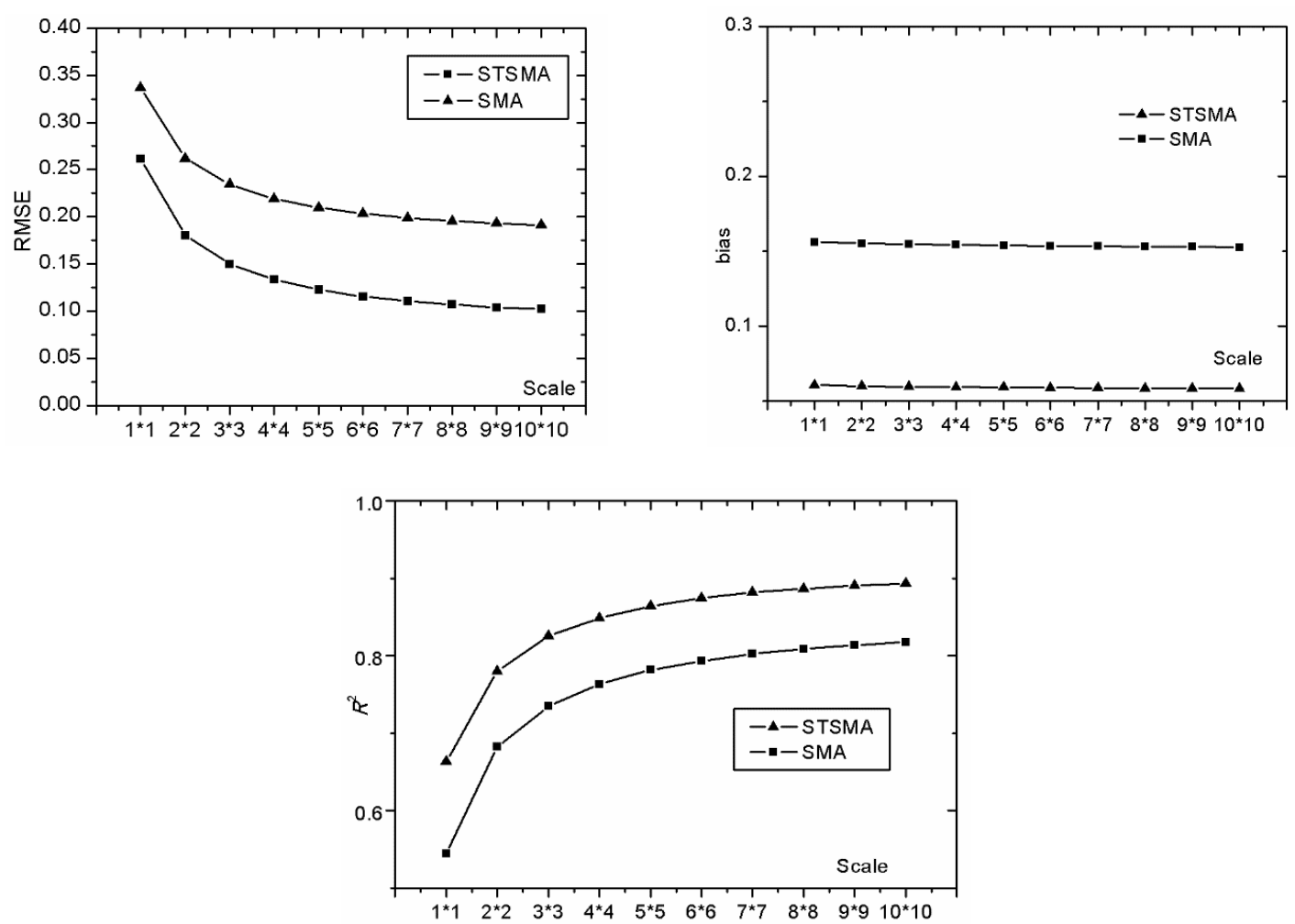

Figure 7. Comparison of cropland estimated by STSMA and SMA applied to MODIS EVI: (a) RMSE, (b) bias, (c) $R^{2}$

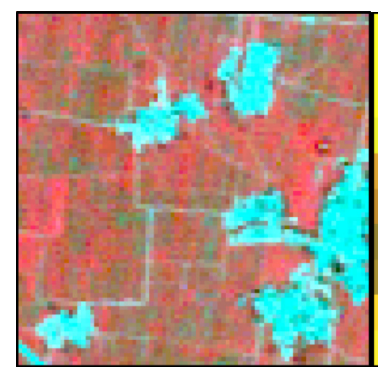

(a)

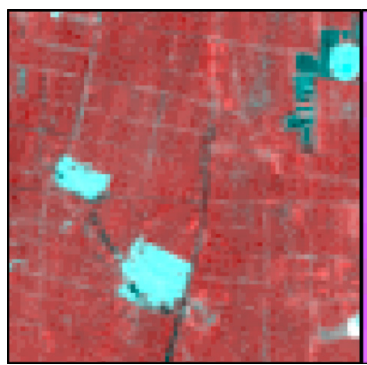

(e)

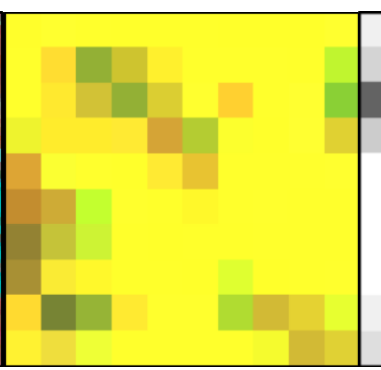

(b)

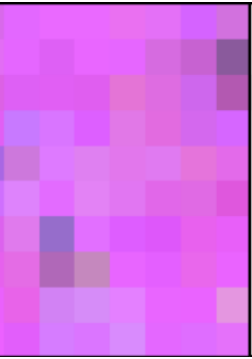

(f)

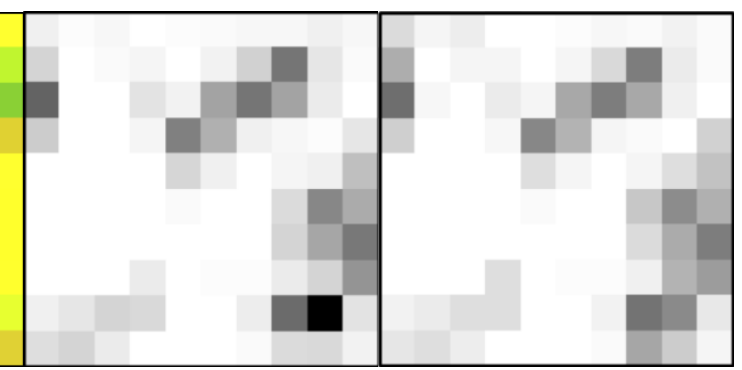

(c)

(d)

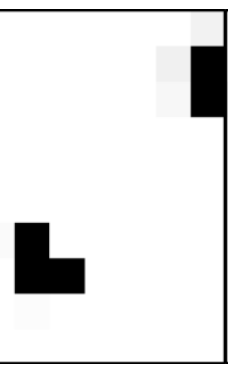

$(\mathrm{g})$

(h) 


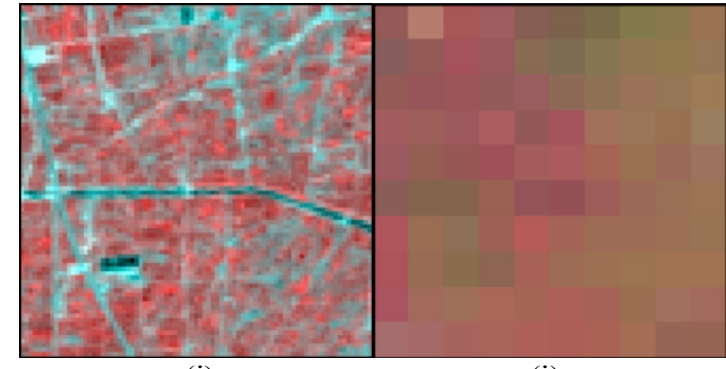

(i)

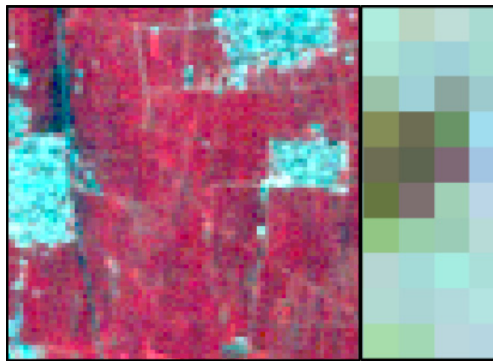

(m)

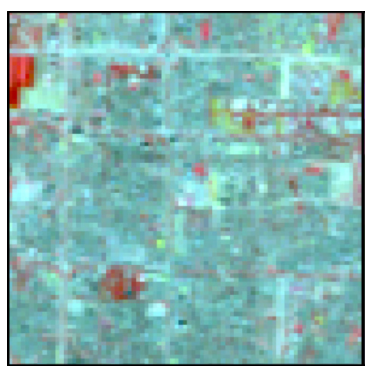

(r) (j)

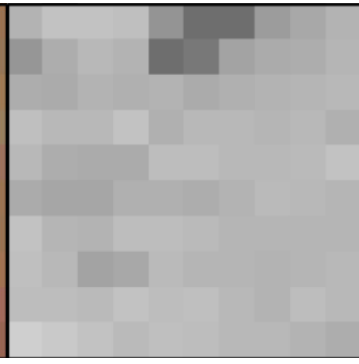

(k)

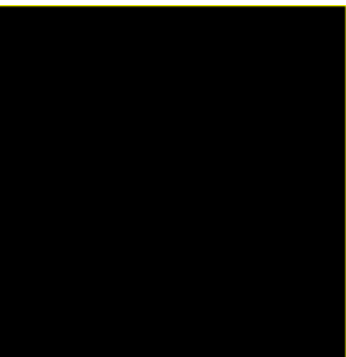

(o)

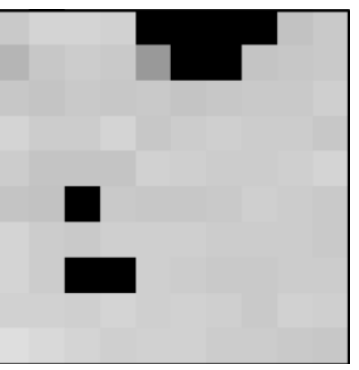

(1)

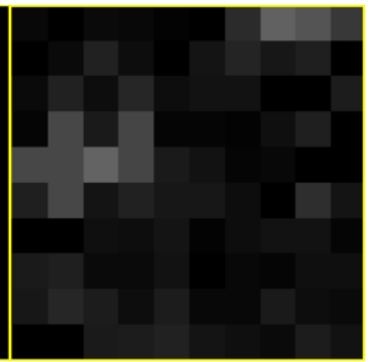

(p)

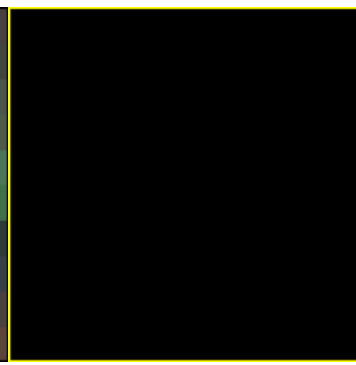

(t)

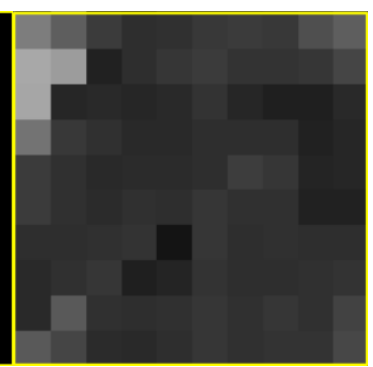

(u)

Figure 8. Five subviews chosen to analyze the results using STSMA and SMA (Landsat bands combination: $\mathrm{RGB}=4,3,2)$. (a)-(d) is the plot of region where SSC is dominated, where (a) is the TM remote sensing image,

(b) is the MODIS time-series data combined as 17, 13, 9 bands responding to September, June and May, respectively. (c) is the cropland fraction mapping using STSMA, (d) is the cropland fraction mapping using SMA. (e)-(h) is the sub-view where DSC landscape is dominated. (i)-(l) is the sub-view where SDSC landscape is dominated. (m)-(p) is the sub-view where NV landscape is dominated. (r)-(u) is the sub-view where Non_V landscape is dominated

\section{Conclusions}

A STSMA model was developed in this paper to map cropland on a sub-pixel scale using the MODIS-EVI time series data. The land cover thematic map extracted from MODIS data is used as the prior-knowledge to define the strata, SSC, DSC, SDSC, NV and Non_V are dominated. In SSC region, the endmember set of SSC and Non_V is defined and input into SMA to estimate cropland, whereas in DSC region, DSC and Non_V as the constrained endmember for SMA to generate the cultivated land map. The SDSC is the traditional region where the mosaic of SSC, DSC NV and Non_V, using the global endmember set which is same as the convectional SMA. The NV and Non_V are the particular regions where the cropland fraction is set zero because there are classified as no cropland in these areas which can be defined from LCM thematic map.

Compared to the conventional SMA method, the proposed STSMA method could achieve better performance for cropland distribution mapping, lower RMSE and bias and higher $R^{2}$, in estimating cropland land. In DSC and SDC area, STSMA estimated the cropland fraction which is close to "actual value" derived from Landsat TM. In NV and Non_V region, STSMA produced almost zero cropland fraction that could eliminate the influence of natural vegetation and non-vegetation, such and tree and urban area, whereas SMA model usually overestimates the cropland fraction due to above factors. Furthermore, thanks to the prior-knowledge introduced by classification, endmember colinearity which is evitable for conventional SMA could be solved at some degree using the strata to define the suitable endmember set to unmix the mixed pixel. Our proposed STSMA demonstrated the great potential for providing more accurate cropland information than the traditional SMA, which can applied for further study on cropland information extraction in southern region of China, where more 
fragmented field parcels condition is dominated.

Some measurements should be carried out to remove STSMA limitation. First of all, the accuracy y of LCM is a critical and basic factor to influence the performance of STSMA for cropland mapping. Some SDSC pixels were misclassified as SSC and DSC pixels, leading to cropland fraction overestimation. How to obtain higher accurate classification result to define the strata is the next research emphasis. Furthermore, the colinearity problem may be addressed at some degree from STSMA, while the global endmember sets are still not suitable for each mixed pixels. According to Jia et al.'s viewpoint (2010), to select the local endmember from the focused mixed pixel might be an effective way to solve the problem, which can be introduced for the further study.

\section{Acknowledgements}

This research was supported by the Natural Science Foundation of China (Grant No. 41301444), the Major Project of High-resolution Earth Observation System and "Youth Yingcai Plan" from institution of higher learning of Beijing. We thank the anonymous reviewers and editors for their valuable comments and suggestions on improving the quality of this paper.

\section{References}

Arvor, D., Jonathan, M., Meirelles, M. S. P., Dubreuil, V., \& Durieux, L. (2011). Classification of MODIS EVI time series for crop mapping in the state of Mato Grosso, Brazil. International Journal of Remote Sensing, 32, 7847-7871. http://dx.doi.org/10.1080/01431161.2010.531783

Biradar, C. M., \& Xiao, X. (2011). Quantifying the area and spatial distribution of double-and triple-cropping croplands in India with multi-temporal MODIS imagery in 2005. International Journal of Remote Sensing, 32, 367-386. http://dx.doi.org/10.1080/01431160903464179

Bondeau, A., Smith, P. C., Zaehle, S., Schaphoff, S., Lucht, W., Cramer, W., ... Reichstein, M. (2007). Modelling the role of agriculture for the 20th century global terrestrial carbon balance. Global Change Biology, 13, 679-706. http://dx.doi.org/10.1111/j.1365-2486.2006.01305.x

Carfagna, E., \& Gallego, F. J. (2005). Using remote sensing for agricultural statistics. International Statistical Review, 73, 389-404. http://dx.doi.org/10.1111/j.1751-5823.2005.tb00155.x

Chen, J., Jönsson, P., Tamura, M., Gu, Z., Matsushita, B., \& Eklundh, L. (2004). A simple method for reconstructing a high-quality NDVI time-series data set based on the Savitzky-Golay filter. Remote Sensing of Environment, 91, 332-344. http://dx.doi.org/10.1016/j.rse.2004.03.014

Jia, X., Dey, C., Fraser, D., Lymburner, L., \& Lewis, A. (2010). Controlled spectral unmixing using extended Support Vector Machines. Hyperspectral Image and Signal Processing: Evolution in Remote Sensing (WHISPERS), 2010 2nd Workshop (pp. 1-4). IEEE. http://dx.doi.org/10.1109/WHISPERS.2010.5594843

Lobell, D. B., \& Asner, G. P. (2004). Cropland distributions from temporal unmixing of MODIS data. Remote Sensing of Environment, 93, 412-422. http://dx.doi.org/10.1016/j.rse.2004.08.002

Mountrakis, G., Im, J., \& Ogole, C. (2011). Support vector machines in remote sensing: A review. ISPRS Journal of Photogrammetry and Remote Sensing, 66(3), 247-259. http://dx.doi.org/10.1016/j.isprsjprs.2010.11.001

Nuarsa, I. W., Nishio, F., \& Hongo, C. (2011). Spectral characteristics and mapping of rice plants using multi-temporal Landsat data. Journal of Agricultural Science, 3(1), 54-67. http://dx.doi.org/10.5539/jas.v3n1p54

Ozdogan, M., \& Woodcock, C. E. (2006). Resolution dependent errors in remote sensing of cultivated areas. Remote Sensing of Environment, 103, 203-217. http://dx.doi.org/10.1016/j.rse.2006.04.004

Pan, Y. Z., Hu, T. G., Zhu, X. F., Zhang, J. S., \& Wang, X. D. (2012a). Mapping cropland distributions using a hard and soft classification model. IEEE Transactions on Geoscience and Remote Sensing, 50(11), 4301-4312. http://dx.doi.org/10.1109/TGRS.2012.2193403

Pan, Y., Li, L., Zhang, J., Liang, S., Zhu, X., \& Sulla-Menashe, D. (2012b). Winter wheat area estimation from MODIS-EVI time series data using the Crop Proportion Phenology Index. Remote Sensing of Environment, 119, 232-242. http://dx.doi.org/10.1016/j.rse.2011.10.011

Potgieter, A. B., Apan, A., Hammer, G., \& Dunn, P. (2010). Early-season crop area estimates for winter crops in NE Australia using MODIS satellite imagery. ISPRS Journal of Photogrammetry and Remote Sensing, 65, 380-387. http://dx.doi.org/10.1080/10.1016/j.isprsjprs.2010.04.004

Rashed, T., Weeks, J. R., Gadalla, M. S., \& Hill, A. G. (2001). Revealing the anatomy of cities through spectral 
mixture analysis of multispectral satellite imagery: a case study of the Greater Cairo region, Egypt. Geocarto International, 16, 7-18. http://dx.doi.org/10.1080/10106040108542210

Ren, J., Chen, Z., Zhou, Q., \& Tang, H. (2008). Regional yield estimation for winter wheat with MODIS-NDVI data in Shandong, China. International Journal of Applied Earth Observation and Geoinformation, 10, 403-413. http://dx.doi.org/10.1016/j.jag.2007.11.003

Roberts, D. A., Gardner, M., Church, R., Ustin, S., Scheer, G., \& Green, R. O. (1998). Mapping chaparral in the Santa Monica Mountains using multiple endmember spectral mixture models. Remote Sensing of Environment, 65, 267-279. http://dx.doi.org/10.1016/S0034-4257(98)00037-6

Sakamoto, T., Yokozawa, M., Toritani, H., Shibayama, M., Ishitsuka, N., \& Ohno, H. (2005). A crop phenology detection method using time-series MODIS data. Remote Sensing of Environment, 96(3), 366-374. http://dx.doi.org/10.1016/j.rse.2005.03.008

Tan, P., Lymburner, L., Thankappan, M., \& Lewis, A. (2011). Mapping Cropping Practices Using MODIS Time Series: Harnessing the Data Explosion. Journal of the Indian Society of Remote Sensing, 39, 365-372. http://dx.doi.org/10.1007/s12524-011-0124-0

Thenkabail, P. S., \& Wu, Z. (2012). An Automated Cropland Classification Algorithm (ACCA) for Tajikistan by Combining Landsat, MODIS, and Secondary Data. Remote Sensing, 4, 2890-2918. http://dx.doi.org/10.3390/rs4102890

Van de Voorde, T., De Roeck, T., \& Canters, F. (2009). A comparison of two spectral mixture modelling approaches for impervious surface mapping in urban areas. International Journal of Remote Sensing, 30(18), 4785-4806. http://dx.doi.org/10.1080/01431160802665918

Van der Meer, F. D., \& Jia, X. (2012). Collinearity and orthogonality of endmembers in linear spectral unmixing. International Journal of Applied Earth Observation and Geoinformation, 18, 491-503. http://dx.doi.org/10.1016/j.jag.2011.10.004

Wardlow, B. D., Egbert, S. L., \& Kastens, J. H. (2007). Analysis of time-series MODIS $250 \mathrm{~m}$ vegetation index data for crop classification in the US Central Great Plains. Remote Sensing of Environment, 108, 290-310. http://dx.doi.org/10.1016/j.rse.2006.11.021

Wardlow, B. D., Kastens, J. H., \& Egbert, S. L. (2006). Using USDA crop progress data for the evaluation of greenup onset date calculated from MODIS 250-meter data. Photogrammetric Engineering and Remote Sensing, 72, 1225-1234. http://dx.doi.org/10.14358/PERS.72.11.1225

Wästfelt, A., Tegenu, T., Nielsen, M. M., \& Malmberg, B. (2012). Qualitative satellite image analysis: Mapping spatial distribution of farming types in Ethiopia. Applied Geography, 32, 465-476. http://dx.doi.org/10.1016/j.apgeog.2011.04.001

Wu, C., \& Murray, A. T. (2003). Estimating impervious surface distribution by spectral mixture analysis. Remote Sensing of Environment, 84, 493-505. http://dx.doi.org/10.1016/S0034-4257(02)00136-0

Yang, F., Matsushita, B., \& Fukushima, T. (2010). A pre-screened and normalized multiple endmember spectral mixture analysis for mapping impervious surface area in Lake Kasumigaura Basin, Japan. ISPRS Journal of Photogrammetry and Remote Sensing, 65, 479-490. http://dx.doi.org/10.1016/ j.isprsjprs.2010.06.004

Zhang, J., He, C., Zhou, Y., Zhu, S., \& Shuai, G. (2014). Prior-knowledge-based spectral mixture analysis for impervious surface mapping. International Journal of Applied Earth Observation and Geoinformation, 28, 201-210. http://dx.doi.org/10.1016/j.jag.2013.12.001

\section{Copyrights}

Copyright for this article is retained by the author(s), with first publication rights granted to the journal.

This is an open-access article distributed under the terms and conditions of the Creative Commons Attribution license (http://creativecommons.org/licenses/by/3.0/). 